\title{
Unlocking a lock-in: towards a model of technological succession
}

\author{
Paul Windrum \\ MERIT \\ University of Maastricht \\ The Netherlands
}

E-mail correspondence: P.Windrum@merit.unimaas.nl

The author would like to thank Nicolas Jonard, Peter Swann, Rene Kemp and Petra Ahrweiler for their comments. As usual, all errors are the responsibility of the author. 


\begin{abstract}
This paper has three objectives. First, it seeks to set an agenda in which technological successions can be meaningfully discussed. Second, it aims to establish the necessary conditions under which a technological succession may occur. Third, in establishing this set of conditions, the paper identifies some useful analytical tools which could be employed in a formal model of technological transitions.
\end{abstract}

Opening up the research agenda on transition phases from established to new technologies is a key issue in discussions of technological evolution and its impacts on society and the environment. Given the increasing returns to adoption enjoyed by an established technology, it is necessary to investigate the conditions under which it is possible for technological succession to occur. In so doing, the paper takes on board the important insights into increasing returns to adoption and path dependency made by the lock-in literature but places these within a new, more general, historical setting.

A number of steps need to be taken when preparing the ground for a formal model of technological succession. First, one must have a clear definition of the elements necessary to operationalise the concept of succession in the social domain. Second, the paper offers an interpretation of previous work on socio-technology paradigms, whereby these are viewed as a set of coupled selection mechanisms that shape the rate and direction of technological innovation. Third, a socio-technical matrix approach is used in order to appreciate the way in which agents - with heterogeneous preferences - compare rival technologies and make their selections. Finally there is a discussion of factors that may produce inertia to technological switching. With these elements in place, the paper argues, we can begin to explain how technological learning generates long period of stasis punctuated by sudden bursts of rapid technological change.

Key words: technological innovation, succession, lock-in, co-evolution, population learning 


\section{Introduction}

Schumpeter laid stress on the importance of technological discontinuities in economic history. In contrast to Marshall, who on the front page of his 'Principles of Economics' stated that Natura non facit saltum (Nature does not leap), Schumpeter argued that "evolution is lopsided, discontinuous, disharmonious by nature... studded with violent outbursts and catastrophes... more like a series of explosions than a gentle, though incessant, transformation" (Schumpeter, 1939, p. 102). Schumpeter did not disagree that there are long periods of gradual development that are marked by the incremental development of dominant technologies. However, he stressed that such period are punctuated by short bursts in which new technological products, processes and associated knowledges replace the existing regimes. It is these bursts of 'creative destruction' that truly drive the system in a new direction. Such a shift "so displaces its equilibrium point that the new one cannot be reached from the old one by infinitesimal steps. Add successively as many mail coaches as you please, you will never get a railway thereby" (Schumpeter, 1939, p.37).

Schumpeter's view of economic evolution clearly has much in common with the ecological theory of punctuated equilibrium later put forward by Gould and Eldridge (1977). "[O]nce they appear, species tend not to change very much at all. They may last 5 or 10 million years - sometimes even longer - and yet, while a few might undergo the sort of gradual, 'progressive' modification we have come to expect of evolution, most will stay pretty much as they were when they first evolved... But the mid-Paleozoic period shows us that the individual instances of species-stability 'punctuated' by occasional bursts of speciation... have immediate consequences for the ecological organisation, and thus the ecological history, of life" (Eldridge, 1987, p.82).

It is perhaps surprising, then, that neo-Schumpeterian economists have to a very large extent either played down, or else ignored completely, the issue of technological succession. Andersen (1990) observes that lip-service is frequently paid to Schumpeter while developing an analysis that is much closer to Marshall's gradualist account of economic evolution. To put it succinctly, they 'bow to Schumpeter while talking of Marshall'. This is certainly true of the literature on technological lock-in that has been developed over the last 15 years. This analysis of the diffusion of contemporaneous goods and standards is unconcerned with questions relating either to the existence of prior technologies, or to the way in which new technologies are able to displace older technologies. Yet one would presume that there is much that can be usefully said about the dynamics of technological succession through a discussion of increasing returns to adoption and path dependency ${ }^{1}$.

\footnotetext{
${ }^{1}$ There are a handful of noteworthy exceptions of which I am aware. These are Foray and Grübler, (1990), Shy (1996) and Islas (1997).
} 
As well as being important in developing a broader understanding of economic evolution, such issues are particularly pertinent in fields such as environmental studies, where the interest is how to replace incumbent technologies with new, more environmentallyfriendly ones. Reformulating the research question in order to addressing the unlocking of a technological lock-in may have a similar effect to turning around a telescope in order to see the wider picture. Thus, rather than discarding the insights made by the lock-in literature, our aim here is to recast these within a broader context.

According to Shy (1996) three issues are likely to affect the timing and frequency of new technology adoptions. These are (i) the technology growth rate and consumer population size, (ii) the degree to which a new technology is compatible with an incumbent technology, and (iii) consumers' degree of substitution between network size and a more advanced technology. Section 2 reviews the standard lock-in account of technological innovation and notes some of the criticisms of it that have been raised by previous authors. Sections 3 and 4 examine the concept of ecological succession and identify the steps that need to be taken in order to translate and operationalise the concept in the social domain. In addressing issue (i), section 5 questions the standard assumption of a linear relationship between network externalities and installed user base, opening up the possibility of a technological succession. Section 6 addresses issue (ii), distinguishing between incremental change due to the replacement of a system component and radical innovation that is a consequence of system succession. In addressing issue (iii), section 7 outlines a socio-technical matrix approach to the study of technological innovation. This extends the Lancaster (1971) characteristics approach to incorporate the various social agents that are found in the business, regulation, and wider societal selection environments. Section 8 then outlines a co-evolutionary model that uses this approach to explore the dynamics of technological succession.

\section{The theory of technological lock-in}

Over the last decade and a half much attention has been given to the consequences of incremental learning. Empirical studies conducted by, amongst others, David (1985), Arthur (1988), Winter (1984), Nelson (1993), and Lundvall (1992) have highlighted the operation of incremental learning at the micro, meso and macro levels in case studies of individual firms, technologies, industries and national innovation systems. In combination with increasing returns to adoption and path dependency, incremental learning has a number of important consequences for market-driven de facto standards, particularly with respect to the dominant designs that emerge over the course of a product life cycle. 
Prior to the work on increasing returns to adoption and path dependency, a number of claims had been made regarding the optimality of the market mechanism. Following Silverberg (1988), the basic argument is readily illustrated by Fisher's replicator dynamic algorithm (Fisher, 1930):

$$
\begin{aligned}
& \mathrm{x}_{\mathrm{i}}=\mathrm{Ax}_{\mathrm{i}}\left[\mathrm{E}_{\mathrm{i}}-\langle\mathrm{E}\rangle\right], \quad \mathrm{i}=1 \ldots \mathrm{n} \quad \text { (equation 1) } \\
& \text { where }\langle\mathrm{E}\rangle=\left(\sum \mathrm{x}_{\mathrm{i}} \mathrm{E}_{\mathrm{i}}\right)
\end{aligned}
$$

The population is composed of $\mathrm{n}$ distinct competing 'species'. $\mathrm{x}_{\mathrm{i}}$ represents the proportion of species $i$ in some population of interacting species and $E_{i}$ its related reproductive fitness. $\langle\mathrm{E}\rangle$ is the reference average fitness level of the species. A species with above-average fitness will grow in relative importance while those with belowaverage fitness will contract. The average fitness of the population is itself a moving target because $\langle\mathrm{E}\rangle$ in turn changes in response to changes in species frequencies.

A quite simple and straight forward connection can be made with models investigating the emergence of dominant designs. If the Ei's are simple constants then it can be shown that the species with the highest fitness will displace all the others and that average fitness will increase monotonically over time. By taking equation 1 and giving economic interpretations to its primary components, neo-Schumpeterians have applied the equation to the study of market selection and relative product competitiveness (typically defined as a combination of price, quality, delivery schedules, advertising and other variables). Working with an initially complete set of alternative product designs, the model suggests that market selection will work to reduce the number of surviving designs until, in the limit, there is convergence to a single, 'dominant' design. What is more, the market mechanism will select that design which is optimal for a given set of consumer preferences and production constraints. The result would appear to be an economic parallel to Fisher's 'Fundamental Theorem of Natural Selection' (Metcalfe, 1984).

The pioneering work of David (1985) and Arthur (1987, 1988) on increasing returns to adoption and path dependency questioned this result. Both authors highlighted the extent to which agents build on their existing (often tacit) knowledge bases, limiting their patterns of search within local knowledge domains, the result being an incremental construction of new competences. In the presence of increasing returns to adoption, path dependent learning can readily lead to a lock-in on sub-optimal technologies. What is more, small chance events (i.e. random and unpredictable) that occur in the early stages of a technology's history can fundamentally affect its development and diffusion. Arthur's discussion of the impact of such chance events in the car industry - where petrol, steam and electric battery engines were once rival technological options - is particularly provocative (Arthur, 1988). 
While the original studies of David (1985) and Arthur (1988) respectively focused on the QWERTY keyboard and the petrol car engine, subsequently studies have extended the analysis to other technologies. Two of the most commonly cited exemplars are the technological battles between Sony Betamax and JVC VHS video recorders, and the IBM PC versus the Apple Macintosh. In both cases there was a lock-in to a technology which, even at the time, was widely recognised to be the sub-optimal choice. At first these behaviours appear to contrast sharply with the discussion of Fisher's replicator dynamic algorithm (equation 1). However it is quite easy to link the two. Fisher's Law is only valid for constant fitness functions. A variety of quite different behaviour can arise when selection is frequency-dependent, i.e. where fitness depends on population shares (including a species' own share). These behaviours can then include the emergence of multiple equilibria and lock-in to sub-optimal solutions.

While this literature has yielded a series of important insights with regards to selection between the rival variants of a new technology, a number of criticisms have been made of the formal Arthur model described in Arthur, Ermoliev and Kaniovski (1987) and Arthur (1989). First, the model only takes into account contemporaneous technologies and proceeds by assuming that all rival variants are present at time $t_{0}$ (Foray, 1989). This leads to a rather strange juxtaposition. While Arthur and other lock-in writers are keen to emphasise that 'history matters' in non-ergodic, path dependent systems, the models they have developed are strangely ahistorical in nature. Two important features of technological competition are left unexplored. Given that it is most unlikely that all variants will be present at the outset, what are the consequences of different ages of rival technologies on the selection process? More specifically, what strategies can be used by the producer of a new technology to overcome the lock-in externalities enjoyed by a rival producing an older, well established technology? (Foray and Grübler, 1990). Neither question is addressed by the Arthur model because, once a lock-in occurs, it is thought to be irreversible.

A second criticism, raised by Islas (1997), concerns the lack of attention given to largescale external events "such as war or powerful government action favouring another technological option" (Islas, 1997, p.51). Due to its focus on market phenomena, the lockin literature generally neglects the important role that can be played by government in shaping the standards setting process. One obvious example is the effect of government legislation with respect to negative externalities, such as environmental pollution, generated during fabrication or at the point of use. However a variety of public sector institutions, such as public research labs and universities, may also contribute to the innovation process at certain stages of the life cycle, fundamentally affecting the evolution of a product. Third, extending this criticism, the literature omits a whole series of social factors and agents that shape the direction of technological change. Again one must consider how the literature relates the large body of research that has been conducted by historians, sociologists and others on technological innovation. 


\section{Ecological Succession}

The concept of ecological succession provides a useful metaphor for thinking about technological competition. It is discussed in some detail in this section, the concept's main elements being carefully delineated. This is necessary in order to identify the steps which need to be taken in order to translate and operationalise the concept in the social domain.

The concept of ecological succession was first proposed by the American ecologist F.E. Clements (1936). An ecosystem begins its development following the emergence of a new area, such as a shingle bar or sandbank, that is suitable for colonisation. Due to the severity of the physical environment, only a few of the invading plant species are capable of survival. A species poor plant community means there are insufficient resources to sustain herbivores and, in turn, carnivores. Biomass (total living matter) is therefore low. Over time the presence of early plant colonisers begins to modify the microclimate of the environment, improving the organic matter of the soil, reducing the effects of wind and raising relative humidity at the soil surface, which in turn leads to less severe temperature fluctuations (both diurnally and seasonally). This paves the way for successive waves of new plant invaders that alter the composition of the plant community. As well as the overall number of species increasing as these invaders carve out new niches for themselves, these species displace earlier colonisers. For example, grasses and other short-lived opportunist colonisers give way to more robust, longer-lived plant species such as shrubs and trees. The invasion of such plant species brings new opportunities for animals. The canopy may develop a series of layers and the microclimate beneath becomes varied and complex. The changes result in the production of a physically diverse environment that is rich in microhabitats for a wealth of animal species. (Cox and Moore, 1985).

In the early stages of a succession, vegetation increases more rapidly than animal activity and the microbial components of the ecosystem, the excess of productivity over respiration leading to an accumulation of biomass (Odum, 1969). The ecosystem reaches a climax state when the total respiration of plants, herbivores, carnivores and decomposers is equivalent to the gross productivity of the vegetation. Eventually the climax community evolves and the creation of new ecological niches ceases. Once a climax community is established it tends to run on virtually unchanged until an extinction event disrupts the system. If the event is severe enough then many species may become extinct. After relatively mild extinctions, replacement ecosystems tend to resemble those they have replaced because close relatives are still available to stock the habitat. More severe extinctions lead to more radical changes in the complexion of the replacement ecosystems that emerge. 
If a new species is to invade a climax community it must displace an existing species from its niche without the help of changes in the environment that are unfavourable to the current occupant. Consequently climax communities are far less open to invasion than earlier stages of succession. As Nicolis and Prigogine (1977) note, the new invaders must have a better capability of exploiting the same resources offered within a niche. In other words, they must be able to do something 'more' or 'better' - whether it be capturing a certain type of prey, reproducing or avoiding death - than the previous incumbent. As a consequence, the fitness of successive species occupying a given niche will increase over time.

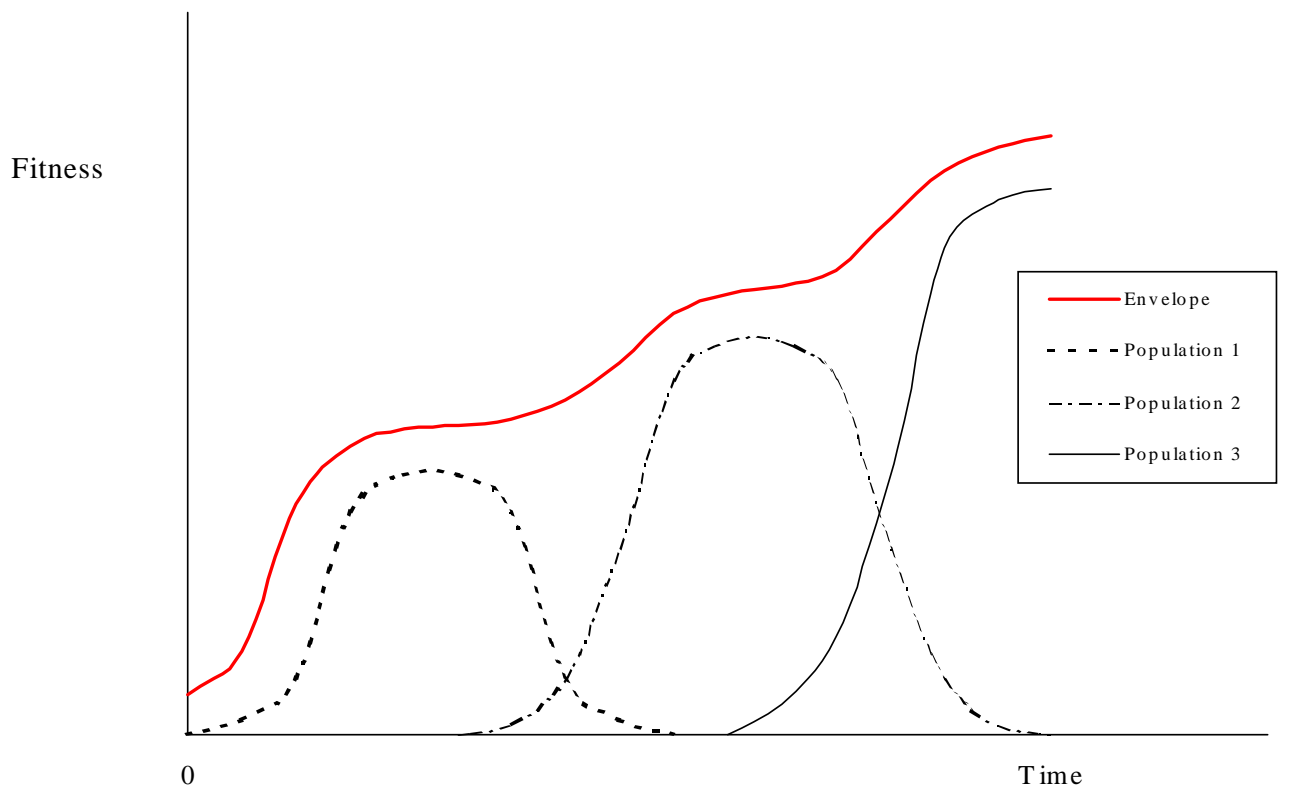

Figure 1. A niche successively occupied by species of increasing fitness

One can readily produce a similar looking diagram by replacing fitness with market share on the vertical axis, thereby plotting the changing relative market shares of successive technologies over time. For example, Grübler has done this for primary energy sources and transport (Grübler et al, 1988; Grübler, 1990). Thus, for example, the horse was replaced by the train, which was in turn succeeded by buses and then cars as the dominant mode of land-based transport in the US and Western Europe. Although superficially similar, such diagrams depicting relative shares are not the same as figure 1. Mapping succession in the socio-economic domain requires a careful definition of 'niche', 'species' and 'fitness'. It is to these issues that we next turn. 


\section{Technological Succession}

By ignoring the possibility of pre-existing technological incumbents, the Arthur lock-in model limits its study to the competitive conditions of the first 'colonisation' phase. Here competition is between new invading species within a virgin, if somewhat inhospitable and uncertain, environment. They do not have to concern themselves with the problem of displacing a well-established incumbent species, only with the competition offered by other new arrivals. It is extremely doubtful whether this is likely to be the typical case. Generally speaking, it is far more likely that competition requires new technology entrants to formulate strategies that displace existing incumbents using older technologies as well as strategies to compete against variants of the new technology offered by other new entrants.

Discussions of technological succession require a careful definition of the selection environment in which innovating firms operate. $\mathrm{Rip}^{2}$ has highlighted three relevant dimensions in his definition of socio-technical niches. In addition to the business environment (dominated by market relationships with customers and suppliers) there is a regulation environment (government and other regulatory bodies) and a wider societal environment (consumer organisations, environmental groups, the media, public opinion leaders and independent scientists).

Let us consider the case of the car in order to illustrate how the development of a sociotechnical niche requires a negotiation of multiple interdependencies in these three selection environments. There are a number of characteristics which distinguish the car from other modes of urban transport. First, it offers the user a flexible, single source method of travelling between any two points. Second, it is an explicitly individual, rather than collective, form of mobility. Turning the offer of flexible, individual mobility into a reality requires, amongst other things, an infrastructure of roads and refuelling points. This means various industries and technologies are necessary to underpin car transport, e.g. road and bridge construction, oil refining and distribution, and electricity generation. These are additional to the materials technologies in plastics, metals, rubber and glass used in car fabrication.

The efficient running of a car-based transport system requires the co-ordination of traffic flow and parking spaces. The former includes support services such as road lighting, road maintenance, traffic signals and signs, repair garages, and break-down services. These are provided by a mix of private and public sector providers. Indeed a complicated regulation environment is present in nearly all countries, with a combination of national and local government regulatory bodies responsible for the formulation and delivery of urban and environmental planning programmes covering road construction, urban development and traffic control. Public bodies are additionally involved in the provision of safety-related

\footnotetext{
${ }^{2}$ Rip (1992), Deuten, Rip and Jelsma (1997), and Rip and Kemp (1998).
} 
functions such as proficiency tests for drivers, regular mechanical tests for car safety, road police, and accident and emergency services. Finally, a system of taxation operates to levy car users for these publicly provided goods.

One should add that social and technological lock-in to the car has been actively supported by successive governments in the US and Europe throughout the post-war era. The development of the car, rather than collective modes of transport, was viewed as the most effective means of increasing mobility (Rip and Kemp, 1998). The car was "a culturally and politically constructed symbol of modernity, associated with notion of freedom, democracy and masculinity" (Rip and Kemp, 1998, p.335). As an icon of modernity, the car was perceived as part of a wider socio-economic change that included, amongst other things, the rise of suburban living and the relocation of branch plant manufacturing and light industry from cities to new out-of-town industrial estates. Somewhat ironically, road construction subsequently became a symbol of urban regeneration once these industries had vacated the traditional industrial districts. As the car became woven ever more finely into the fabric of society, so it changed from being a luxury to a necessity. One can add that the prominence of the car within studies of technological innovation must also reflect its position as an icon of modernity. Indeed Abernathy and Utterback (1975) originally developed their product life cycle theory by extrapolating from, and generalising on, the history of the US car industry.

Of course, as the negative consequences of intensive car use have become ever more apparent, its image has changed to that of a 'necessary evil'. While the wider societal environment (comprising consumer organisations, the media, public opinion leaders, etc.) has not as yet turned away from the car, it is playing an important role in the 'greening' of the car-based transport system. This is evident in a number of ways, such as the development of catalytic converters, lead-free petrol and electronic engine monitoring systems to control pollution emissions. Consumer organisations and the media have also pressed car manufacturers for improved safety features (usually, although not exclusively, for the driver's protection) such as airbags, anti-lock brakes, and the banning of bull bars on $4 \times 4$ vehicles in the UK. Appreciating the web of interrelated commercial, social and political interests that have shaped the development of the car is important when considering the environmental debate that now surrounds the car and the various proposals for alternative modes of transport currently being suggested. Once in place and stabilised over a long period of time, such a web of supporting interests can prove exceedingly difficult to dislodge. 
It should be noted that the conceptual background of Rip's analysis differs significantly from the normal lock-in model. The lock-in model offers an 'internalist' account in which technical factors dominate the innovation process and cause a focusing of innovative activity over time. By contrast, Rip subscribes to an 'externalist' account of technological closure (which he shares with historians and sociologists of technology such as Hughes, MacKenzie and Bijker) which emphasises the extent to which the interests of different social groups shape technology. Rather than being an independent causal factor, a product is a device which mediates between different agents. One cannot understand the emergence and use of a technology, it is argued, without an explicit examination of the way in which the (possibly conflicting) interests of different agents interact through a product. Furthermore, it is the very act of mediating between agents' interests that leads to qualitative change in the product's form over time.

Since selection is a multi-dimensional phenomenon in socio-technical systems, it follows that the relative fitness of a technology must also be multi-dimensional. Rosenberg and Frischak observe that "New inventions are typically very primitive at the time of their birth. Their performance is usually poor, compared to existing (alternative) technologies as well as to their future performance" (Rosenberg and Frischak, 1983, p.147). The literature on technology standards highlights the extent to which the network externalities enjoyed by users of an established technology make the costs of switching to a new technology prohibitive, effectively locking-out a new technology that is potentially superior (Katz and Shapiro, 1985, 1986; Farrell and Saloner, 1985, 1986). On the production side, an existing technology also enjoys both static and dynamic economies of scale (due to learning by doing and using) that are not initially open to a new technology. One should also not overlook the inter-technology relationships highlighted by Rosenberg (1982) as being crucial to an understanding of innovation and productivity gains - a point subsequently taken up by Freeman and Perez (1988) in their discussion of economic longwaves. As well as having time to entrench itself materially, an established technology can entrench itself intellectually through the evaluation norms used by political, economic and other social agents (Foray and Grübler, 1990). Together, such effects make invasion of an existing niche extremely difficult.

Turning to a definition of 'species' in socio-technical systems, Windrum and Birchenhall (1998) observe that a necessary (though not necessarily sufficient) condition for a sustainable market niche is the support of a distinct user group that is attracted by the functionality offered by a technology in use. Technological succession is therefore concerned with the functional replacement of an existing product or process. 


\section{The potential for a technology shift: bounded returns to adoption}

The Arthur model suggests that, in the face of increasing returns to adoption, nothing can overcome a technology once it gets ahead and becomes embedded. However Bassanini and Dosi (1998) show that Arthur's lock-in result only strictly applies when returns are linearly increasing and there is homogeneity of consumer preferences (or at least the degree of heterogeneity is small). There are various reasons why diminishing returns may begin to set in at some point - or, in Arthur's language, that increasing returns to adoption are at some point bounded from above.

According to Swann (1998), it is very unlikely that utility will be proportional to the size of the user base. There are two special conditions under which a linear relationship will hold, but neither of these is particularly plausible. One condition is that there is an equal probability of all nodes in the network contacting each other. The other condition is that the diffusion of technology usage is identical across all types of users. Again it is very unlikely that this second condition will hold true. Swann goes on to suggest that a weaker condition for proportionality under which the average utility across possible users is proportional to the size of the network even if utility is not linear for an individual user. However he goes on to show that this is also implausible. The utility of an average user is likely to be an sigmoid function of total network size, or at least logarithmic function where there are diminishing returns to marginal utility.

Frenken and Verbart (1998) additionally point out that returns to adoption are likely to depend on the perceived usefulness of a product in performing a certain task or solving a particular problem. While Arthur (1988) notes this aspect of consumer choice, his model only relates returns to adoption to the size of the installed user base, ignoring the problemsolving capacity of the technology. Applying Thomas Kuhn's theory of scientific paradigms (Kuhn, 1962) to the technological domain, Frenken and Verbart observe that the problem-solving capacity of a technology is also affected by the number of previous adopters contributing to the technology. However it is unlikely that a linear relationship will hold over time. Following Sterman's (1985) discussion of the limits to the problem-solving capacity of scientific disciplines, Frenken and Verbart argue that the functional form of the relationship between learning and the number of adopters is likely to be sigmoid. As the number of contributors increases in the initial phase of its history, so the problem-solving capacity of the user network supporting that technology increases exponentially due to gains in the division of labour and benefits arising from new fields of application. However there is an upper limit to the problem-solving capacity of a user network. As a technology paradigm matures, so co-ordination costs start to outweigh the gains derived through further divisions of labour (Williamson, 1975). The ability to identify and develop new fields of application is similarly limited and anomalies signal open questions that are considered to be beyond solution within the technology's framework. Consequently the growth of problemsolving capacity begins to slow to a standstill. 
The combined effect of the network size and learning capacity suggests that diminishing returns will begin to set in at some point - or, in Arthur's language, that increasing returns to adoption are at some point bounded from above. This is an important observation because the existence of a sigmoid function, or at least an upper-bound log function consistent with a traditional diminishing returns-type argument, opens up the possibility of a consumer population being attracted by the potential of a later technology entrant - a necessary (but not sufficient) condition for a technological succession.

\section{Component replacement and system succession}

One should carefully engage in what Nelson and Winter (1982) have described as appreciative theorising prior to the development of formal mathematical modelling. As well as identifying a set of stylised facts that one would like to replicate as emergent properties of the model, appreciative theorising also provides the basic conceptual and theoretical elements which form the core of the model. Careful attention to appreciative theorising is particularly important when one is engaged in work that is, by its nature, exploratory. There may be little or no guidance from previous research as to what the relevant set of research questions are, or what types of behaviours are important in understanding the observed phenomena. Appreciative theorising therefore incorporates those stylised facts about the world which appear relevant to the task at hand, and draws on various bodies of literature, some of which may lie outside one's own discipline.

Having considered the relationship between the installed user base and the technology growth rate, we next consider the second key relationship identified by Shy (1996); the degree of compatibility between a new technology and an incumbent one. As previously noted, a technological artefact (or 'product') typically comprises a number of subcomponents (or 'modules'). Discussions of compatibility within the lock-in literature and even more so in the related work on network standards ${ }^{3}$ - have almost exclusively focused on technical interface standards between product modules, with perhaps an occasional discussion of user interface standards (e.g. Windrum, 1998). However there is little or no discussion in this literature of functional compatibility. This is unfortunate, though perhaps understandable given the research agenda of the lock-in literature. While this discussion of modular compatibility is certainly important for understanding key aspects of innovation within a particular technological product, it is less so for understanding the dynamics of transition between one technology and another. Here the important issue for consumers is functional compatibility, or functional equivalence, of rival technologies as opposed to the standards governing sub-component interfaces.

\footnotetext{
${ }^{3}$ An additional criticism, not highlighted in section 2, that can be made of the lock-in literature is the lack of overlap that exists between it and the network standards literature pioneered by Katz, Shapiro, Farrell and Saloner. Windrum (1998) argues that there is much that can be gained by linking these two literatures together, although this is an issue for future work.
} 
The distinction becomes even more clear when one considers figures 2 and 3 respectively. In the case of a component replacement within an existing technology system (figure 2) a common interface standard enables one to replace one module with a new, improved module, thereby yielding an improvement in overall quality of the system, while avoiding the need to re-engineer all of the other components that make up the product. This clearly decreases the cost of continuing incremental innovation within an established technology. By contrast, the replacement of an existing system with a new, alternative system (figure 3) is much more likely to bring about the type of economic discontinuity discussed by Schumpeter. Such changes are likely to be associated with radical disjunctures in learning, skills and competence bases - technological succession not only implies a replacement of material artefacts and production processes but also the various types of associated knowledge and power (economic, social and political) associated with the older, incumbent technologies by new assemblages.

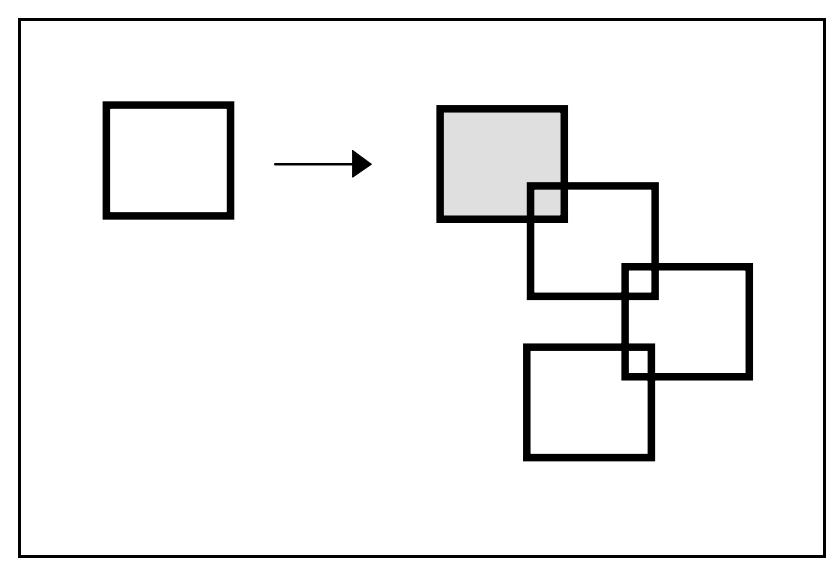

Figure 2. Component replacement within an existing system 


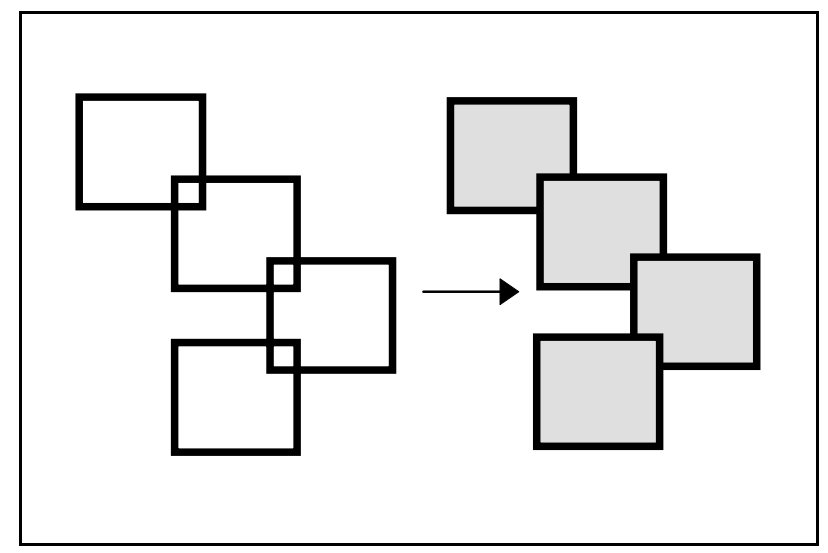

Figure 3. Replacement of the existing system by an alternative system

For technological succession to occur users must be persuaded that the new technology can in some sense better fulfil the product or process function of the older technology. We shall explore the notion of functional equivalence in more detail in the next section. Prior to this we observe that quite different interpretations of what represents a radical or incremental change can arise according to the way in which one defines the 'system'. Take, for example, the work of Tushman. Working with the concept of the dominant design, Tushman seeks to locate the source of technological discontinuities in changes that occur at the subsystem level of a technology ${ }^{4}$. Putting forward a strongly internalist account of technological innovation, he argues that one can locate a clear hierarchy in which particular modules of a product are more important than others ${ }^{5}$. These are denoted by the terms 'core subsystems' and 'peripheral subsystems'. While innovation in core subsystems is likely to lead to a radical improvement in performance, innovation in peripheral subsystems tends to produce only an incremental improvement in performance (Tushman and Murmann, 1998, pp.16, 17). For example, if one wishes to improve the performance of a PC then focusing effort on increasing processing power and/or the performance of the operating system is likely to reap more immediate rewards that focusing on other hardware or software components. Here Tushman and Murmann clearly have a point - we no longer speak of the IBM PC de facto standard but the WinTel standard, i.e. a standard which has at its core a Microsoft Windows operating system and an Intel Processor. As we know, IBM exited 'stage left' quite a while ago.

There is much to commend in Tushman's work. The current paper shares, for example, his interest in distinguishing between radical and incremental change, and draws upon much of the same literature. However it seems that Tushman ultimately ends up

\footnotetext{
${ }^{4}$ See, for example, the discussions contained in Anderson and Tushman (1990), Rosenkopf and Tushman (1994), and Tushman and Murmann (1998).

5 This is a development of the discussion of nested hierarchies of subsystems and 'architectures' of linking mechanisms contained in Clark (1985), Abernathy and Clark (1985), and Henderson and Clark (1990).
} 
discussing how best $R \& D$ effort can be focused in order to maximise investment in a dominant design. Despite his use of the term 'technological discontinuity', his work is concerned with innovation in an existing technology paradigm rather than the dynamics of radical paradigm shifts which so interested Schumpeter. Second, the current paper has already questioned the ability to explain the dynamics of technological succession solely through an examination of the sub-components making up a physical product. For example, in the paper by Tushman and Murmann, it is stated that the internal combustion engine is the core module of the car. A change in this core component would therefore represent a radical innovation that would not only lead to a significant change in measured performance but would require fundamental changes to the other modular elements making up this physical artefact.

How does one account for the development of fuel cell engines under this perspective? The development timetables of the major car manufacturers for fuel cell electric vehicles (FCEVs) have been brought forward following General Motors' announcement that it will have a commercial vehicle ready for sale in the year 2004 (Autocar, 1999). Yet fuel cells do not appear to offer any major performance benefits over the internal combustion engine. Indeed the problem facing GM and others over the next 5 years will be to develop an FCEV with an equivalent power output to that offered by the current generation of internal combustion engines. Hence the first generation of FCEV cars are most unlikely to offer any improvements over conventionally powered cars, whether this be speed, acceleration, torque or any other engine-related performance criterion. It has been suggested that the introduction of FCEVs could open the door to some radical changes in car design. However according to press reports, the first generation of FCEVs will have cells that are conventionally positioned under the bonnet. Thus the stimulus for this innovation does not reside in a radical reconfiguration of the modular components of the product.

Of course, the answer to the question lies in a further 'greening' of the car (section 4 above). There is an attraction in FCEVs for car manufacturers because, at a stroke, it promises to remove the health concerns over exhaust emissions that have placed a serious question mark against the long-term future of the car. The dynamics driving this development are readily accounted for when one looks beyond the physical artefact to the social discourse surrounding the long-term viability of the car. For example, in Rip's framework of coupled selection mechanisms, one sees that manufacturers are responding to selective pressure from three different environments. As well as responding to pressure from governments (the regulation environment), scientific research, environmental and other pressure groups (the wider societal environment) to 'green' the car-based transport system, car manufacturers are simultaneously responding to drivers' demands (the business environment) for an engine whose performance is as good as, or at least close to, that of the internal combustion engine. 
The term 'system' has been used at various points in this paper. What is more, it has been used in a way that suggests it should be delineated from the notion of a single 'product'. For example, the term 'car' has been distinguished from the term 'car-based transport system'. It is now time to explain this distinction and to show how it adds to the discussion of radical versus incremental technological change. Returning to the work of Rosenberg, it is possible to construct an analysis, based on the concept of a technology system, which is very different Tushman's. Like Tushman, Rosenberg notes that a product typically comprises a set of modular components. However Rosenberg goes on to observe that products are rarely used in isolation but interact with other products in order to deliver a final service to the end user. "The importance of these complimentarities suggests that it may be fruitful to think... of these major clusterings of innovations from a systems perspective" (Rosenberg, 1982, p.59).

Rosenberg gives various examples of such systems, some that are product-based, others that are process-based. Here we mention just two examples given by Rosenberg; incandescent lighting and hi-fi systems. Incandescent lighting consisted of four key technologies: the generation of electricity at a central power station, a conductor network for the transmission of power, a meter to measure household consumption of electricity, and a lamp. What distinguished successful inventors-innovators in incandescent lighting, such as Thomas Edison and George Westinghouse, was that they "consciously thought in terms of the entire system, the purpose of which was to deliver cheap illumination into millions of domestic residencies" (Rosenberg, 1982, p.60). As a consequence, both Edison and Westinghouse made major contributions in each of the interrelated technologies making up the system.

More typically, one would expect contributions to be made by a number of different, specialist producers. In his discussion of the hi-fi system, Rosenberg observes that all manner of co-ordination problems can arise when components are produced by different manufacturers. Rather than pursuing this particular issue, we note another issue that is nicely illustrated by the recent history of the hi-fi system. Returning to figure 2 , we observe that the existence of a common interface standard for connecting line-level input sources to amplifiers meant CD players were readily accommodated into the hi-fi chain when first introduced in the early 1980s. Within a decade this system component had replaced the LP turntable as the primary input source of the hi-fi chain. This component replacement had an important impact on the fortunes of turntable manufacturers, some of which disappeared because they did not make the transition from LP to CD quickly enough. Additionally, many users were forced to replace their LP collections with equivalent CD versions ${ }^{6}$. However, from a systems perspective, the replacement of the LP by CD turned out to be an incremental innovation. Despite some early discussions concerning the development of a purely digital hi-fi system, and some experimentation in amplifiers containing built-in

\footnotetext{
${ }^{6}$ It is highly contentious to suggest that CD replaced LP because there was an improvement in performance. The hottest debate in hi-fi circles throughout the 1980s and early 1990s was whether CD actually offered an improvement in sound quality, or whether it made things worse! In the end, events took over this debate because the decision by software producers to only release $\mathrm{CD}$ software effectively reduced consumer choice to just one option.
} 
DACs, the replacement of LP by CD has had little or no perceptible impact on amplifier or speaker technology, or the standard interfaces and connectors that link the system together.

The examples of incandescent lighting and the CD nicely illustrate the difference between system succession and component replacement. In the case of incandescent lighting there was a need to simultaneously develop a new collection of interrelated technologies which together made up an alternative system to the gas-based technology system that previously occupied the market niche for domestic lighting. In contrast to this type of wholesale system replacement, the switch from LP to CD involved the replacement of one component within a well-established system.

Discussions of the economic importance of clusters of new technologies have been highlighted in the literature on economic long-waves which followed the work of Freeman, Clark and Soete (1982). Examples such as incandescent lighting provide the clearest case of system succession, with each element of the system comprising a new and novel technological innovation. A new system may also make use of a number of pre-existing technologies, some of which may have been components which belonged to the incumbent system. For example, the infant car system made use of pre-existing road infrastructures which were part of previous horse and stagecoach system. Indeed, in Europe at least, road infrastructures and their underpinning technologies date back to the Romans, who constructed the first integrated European road network in order to march legions of foot soldiers across their empire.

A component belonging to the incumbent system may be taken up and used in a completely different way by the new technology system. For example, local co-generation heat and power (CHP) systems use the electricity distribution grid as a buffer. This is very different to way in which a grid is used by the traditional, centralised electricity generation system (Weber, 1996). This again highlights the problem of examining a single technology without reference to the system structure in which it is embedded. Working within the dominant design literature Clark (like Tushman) has noted that a product typically contains an architecture which links together individual sub-components (see Clark, 1985; Abernathy and Clark, 1985; Henderson and Clark, 1990). Similarly, one can extend this discussion by observing that a system may also possess an architecture which governs the way a set of inter-related products interact ${ }^{7}$.

In addition to the replacement of existing technological products and/or processes, a technological succession involves the replacement of one system architecture with another. While one or more pre-existing elements may be used by the new system, the contextual

\footnotetext{
${ }^{7}$ De facto and de jure standards are often an important aspect of a system architecture. Standards provide information about the quality and performance of a product or process. This is used a basic input by the designers and engineers working on the other products and processes that comprise a technology system.
} 
understanding of these elements may be completely different. This notion of architecture replacement is clearly similar to Kuhn's definition of a scientific revolution (Kuhn, 1962). According to Kuhn a scientific revolution is associated with a gestalt shift which leads one to see the world in a radically new way. While some theorems of the previous scientific paradigm may be retained, these are understood and viewed in a completely different way by the new scientific paradigm. Extending to the system level Clark's discussion of the impact which a change in product architecture has on knowledge bases and industrial structure, the replacement of entire system architectures and sets of interrelated technologies are likely to result in the types of radical disjunctures in economic, political and social structures described by Schumpeter.

From a systems perspective, the development of FCEV cars is similar to that of the CD. Indeed a major attraction of the FCEV is that changes can be made in this sub-component while leaving alone the other technologies and artefacts - road infrastructures, the support services of road lighting, traffic signals, repair garages, car insurance, break-down services etc. - that make up the car-based transport system. The one related group of producers that will be directly affected by FCEV cars are the major oil companies. It is interesting to note the reactions of Exxon's Corporate Research Director, Ramon Espino, to FCEV cars; "At the beginning of the century we were making oil for kerosene lamps. Where would we be if the automobile had not evolved? In the future we will be making methanol, hydrogen and other alternative fuels" (Autocar, 1999, p.51). Thus Espino plays down the implications of FCEVs, suggesting that the oil companies will be able to exploit core competences in fuel production in order to provide whatever fuel source is required by future generations of FCEVs. Furthermore, the established network of refuelling stations will be able to deliver this fuel source. Perhaps, like the car manufacturers, the oil companies recognise that increasing social pressure against petrol and diesel emissions means the days of the internal combustion engine are numbered. Hence both car manufacturers and oil companies are pinning their hopes on a component change that will secure the future of the car-based transport system well into the 21 st century.

\section{A socio-technical matrix approach}

We now turn to the third factor affecting the timing and frequency of new technology adoptions; the degree of substitution between network size and the performance offered by rival technology systems. A basic precondition for this discussion is a formal analytical framework in which one can appreciate how agents compare alternative technology options. Such a framework is offered in this section. The framework comprises two parts. The first is a technical matrix of performance characteristics that can be constructed for a set of competing technologies. The second is the set of preferences, belonging to members of the various groups making up the selection environment, which evaluate and rank the different cells of the characteristics matrix. In principle such a framework can be used as the basis for both theoretical and empirical 
research.

The suggestion that we try to compare substitutable technologies seems, at first glance, rather unappealing. It is (literally) the attempt to compare apples and oranges. Yet such an activity is performed on a daily basis by consumers as part of the purchasing process. Also, as Shy reminds us, the economic literature contains some important precedents for an analytical treatment of how consumers first compare, and then rank, substitutable goods. In the past the analysis has tended to focus on one characteristic of a good - its price - in order to explain the relative price elasticity of a commodity. Here we are interested in the process by which consumers compare multiple characteristics. What is more, the emphasis in this paper is placed on the characteristics that relate to the functional performance of rival technologies.

The characteristics (or address) approach to modelling product differentiation dates back to Hotelling (1929) and has been used in a number of empirical studies (e.g. Saviotti, 1988; Archibald and Eaton, 1989; Choi, DeSarbo and Harker, 1990; Frenken et al., 1999). The approach is based on an explicit description of individual behaviour where a characteristics model is defined as one in which both commodities and consumers can be described by particular points, or addresses, in an $n$ dimensional character space. Following Lancaster (1971) one can describe a commodity in terms of the bundle of characteristics (or attributes) that it embodies. The important insight of Lancaster is that a commodity is not desired in itself but rather because it offers certain performance characteristics that translate into functionalities that form the basis of selection according to consumers preferences. For example, the basic function of an electric kettle is to boil water. Additionally, the function of the kettle's design is to please the user aesthetically, and so on. A firm competes by offering a combination of characteristics that it believes will be more attractive to consumers than those offered by its rivals. In this way a firm effectively offers consumers a distinct point within a multi-dimensional character space. Product innovation is the means by which firms search this $n$-dimensional character space.

Returning to the social construction approach to technological innovation, one distinguishing feature of this approach is the suggestion that there are a number of selection mechanisms, each belonging to a distinct domain, that affect the evolution of a technology over time. Thus, in addition to the valuations and selections made by consumers, we should extend this analysis to include the other selection environments that influence the 'socio-technical characteristics matrix'. In Rip's framework, for example, these include the valuations and selections made by the 'regulation environment' and the 'wider societal environment'. In order to maximise profits, firms will thus search for the combination of characteristics that satisfies the expressed preferences of these selection mechanisms in addition to the expressed preferences of consumers. 
In order to illustrate what a characteristics matrix might look like, let us consider the car and other land-based transport technologies. Each technology product can be represented as a vector whose elements indicate how much of each attribute is embodied in one unit. This vector is the address of the product in a characteristics space (Anderson et al., 1992). In general there are two types of characteristics which appear to be relevant in discussions about alternative modes of land-based transport - those relating to engine performance, and those relating to mobility. The former group includes characteristics such as maximum speed and fuel efficiency, while the latter includes characteristics such as flexibility of travel and carrying capacity. Given the earlier discussion of environmental concerns about intensive car use, we should also consider the negative biproducts of such technologies. Two characteristics highlighted in section 4 were toxic exhaust emissions and congestion delays affecting mobility.

The next step is to generate data on these characteristics for each rival technology. Limiting the discussion to alternative types of mechanised transport (with or without engines), 6 distinct technologies present themselves - car, bus, train, tram, motorbike and bicycle. The data generated on each of these technologies can be collected together and placed in a single characteristics matrix, as in figure 4.

Product Characteristics

\begin{tabular}{l|lllll} 
& $\begin{array}{l}\text { maximum } \\
\text { speed }\end{array}$ & $\begin{array}{l}\text { fuel } \\
\text { efficiency }\end{array}$ & emissions & capacity flexibility & congestion \\
\hline car & & & & \\
train & & & & \\
bus & & & & \\
tram & & & & \\
motorbike & & & & \\
bicycle & & & &
\end{tabular}

Figure 4. A simple characteristics matrix for land-based transport

As well as the values of the cells changing over time due to the innovative activities of competing firms, it is likely that the dimensions of the matrix will also be subject to change. On the one hand, this may be caused by the emergence of new technologies or the disappearance of existing technologies. On the other hand, the number of characteristics may increase or decrease in number. This expansion/contraction of the characteristics set could again be a consequence of firms' innovation activities, as they seek to differentiate their technologies by offering consumers characteristics that were not previously offered by a rival technology. Alternatively, it could be the consequence 
of an external shock. For example, the relative fuel efficiency of competing transport technologies was given little or no consideration prior to the oil crises of the early 1970s. However this became a characteristic of intense interest, and has remained so, following this exogenous shock.

It would be nice - or at least it would make the analysis much easier - if we could identify one technology that is absolutely better (fitter) than the rival options. There are two conditions - one strong, one weak - under which one technology can be deemed to be absolutely fitter than its rivals;

Condition 1. (strong): the values of all the row characteristics of one technology are higher than the values associated with the alternative technologies.

Condition 2. (weak): the value of at least one characteristic is higher than the values offered by rival technologies, the other values being equivalent to the values offered by rival technologies.

In the spirit of Shy, one might have a two-period overlapping generation (OLG) model in which there are two rival technology systems. There is a fixed number of users who purchase one or other technology in each period. Each person buys a good in the first period and holds on to it in the second period. In the first period there is an established incumbent technology, with a network externality associated with an existing installed user base. Given that it is new, the rival technology has zero externality value in the first period. Departing from the basic Shy model, there is a set of characteristics associated with the two technologies. Suppose, for simplicity, that the two technologies are identical except for one characteristic. Suppose also that this characteristic is only offered by the new technology in each period. There may, for example, be technical reasons why the incumbent technology cannot offer this particular characteristic. This is more than just a simplifying assumption. An important aspect of technological competition is the ability of one technology rival to offer characteristics and functionalities that are not offered by another technology (Swann, 1990). Thus an important precondition for a technological switch may be the ability of new technology to offer characteristics and functionalities that are unattainable using the established technological incumbent. Second, and again departing from Shy, we can allow heterogeneity of preferences within the consumer population. While some users may positively value this characteristic, some may be indifferent or actively dislike it. Fitness then depends on the size of the network externality, characteristics, and users' valuations of these characteristics.

Jonard (1999) has shown that technological succession within such a model will depend on the degree of substitution between the network externality and the characteristic. If network size and characteristic valuation are perfect substitutes then the behaviour of the process will depend on the distribution of valuations of the characteristic by the consumer 
population. If preferences are clustered around a zero or negative value then the new technology will be locked out. In such a case the externality enjoyed by the incumbent technology will outweigh the valuation of the benefits associated with the new characteristic. By contrast, if preferences are clustered around a high, positive valuation then at least some consumers will switch away from old to the new technology in period 1. This will diminish the network externality associated with the incumbent technology in period 2, while simultaneously creating a positive externality associated with the new technology. Running the model over a number of periods there will be a complete switch away from the old to the new technology. What is more, this process will generate an sshaped diffusion curve for the new technology while the market share for the old technology falls to zero.

Unfortunately a simple analytically tractable solution is unlikely to exist in all but the simplest of circumstances. First, as Jonard observes, multiple equilibria solutions will exist where there is a high frequency of intermediate valuations within the consumer population. In such cases it is not possible ex ante to predict whether a market will be shared by the two technologies, whether the externality of the old technology will outweigh the externality effect of the new technology leading to a lock-out or, finally, whether the externality effect of the new technology will outweigh that of the old technology leading to a technological succession. A second issue, which in practice may prove to be even more problematic, is that of relative fitness. While a particular technology may offer a higher value in one or more characteristics cells than its rivals, it may offer lower values in other cells. Again, in the presence of heterogeneous preferences, multiple equilibria solutions may exist in which it is impossible to predict ex ante whether there will be a technological succession, a technological lock-out, or the emergence of multiple market niches.

At this point some sociologists and historians of technology have in the past been tempted to step in and argue that the failure to provide an analytically tractable solution indicates that an economics-based approach is invalid and should be jettisoned altogether. It is pointed out, for instance, that the nature and character of technological closure depends on both the interactions of different agents and the relative power of these different groups. While it is true that an analytically tractable solution may not possible, this does not invalidates the economics enterprise as a whole. Interaction amongst agents and the other criticisms commonly raised by contructivists can in principle be met through the development of multi-agent simulation models.

In the current context this means a second element of a formal analytical framework is required. This is provided by a set of preferences, belonging to members of different social groups, that evaluate and rank the various cell values of the characteristics matrix. It is the combination of technical characteristics and social preference functions that give this approach its name. Preferences are assumed to be defined over all potential characteristics, such that the introduction of a new characteristic can be evaluated. An individual's address is defined by the ideal bundle of characteristics located at a point in n-dimensional character space. This address is analogous to one's home address in 
geographical space, while the disutility due to not consuming the ideal bundle of characteristics is analogous to the transportation costs incurred when travelling from home to a supermarket in order to buy the weekly shopping. Disutility increases with the distance between the individual's address and the commodity's address in characteristics space (Anderson et al., 1992).

Heterogeneity of individual preferences means different individuals will give very different weightings to each characteristic of the socio-technical matrix. Identifying what these weightings are empirically is thus an important aspect of the approach. In situations where this is difficult, simulation exercises provide an additional tool of analysis. To illustrate the implications of heterogeneity on technological selection, let us consider a few examples. The expressed preferences of individuals are likely to give quite different weightings to characteristics such as maximum speed, flexibility, fuel efficiency and emissions. For instance, while a sports car driver may give a very high weighting to maximum speed, (s)he may be relatively unconcerned about other characteristics, such as exhaust emissions. In the most extreme case, (s)he may give 'speed' a maximum weight and all other characteristics a zero weight. Under the weak condition (2) of an absolutely fitter technology, this consumer would never switch to a better technology unless that alternative happens to offer an improvement in this specific characteristic. At the other end of the spectrum, a green consumer may have a completely different preference ordering which is held equally strongly. For example, (s)he may give 'emissions' a maximum weight and all other characteristics a zero weight. Under such conditions it is most unlikely that this user would ever choose any mode of transport other than the bicycle.

Different regulatory bodies exhibit very different priorities in their expressed preferences. For example, there are a number of motorways in Germany - though not all(!) - where no speed restrictions are placed on car drivers. This is certainly not true of surrounding countries. Regulatory controls of exhaust emissions also vary greatly across different countries, and sometimes even within countries. For example, the State of California has the strongest emissions controls in the world, contrasting sharply with a number of other states in the US. Similarly, the road building programmes of different governments vary enormously. These are a key determinant affecting road congestion and have recently become a highly politicised issue in countries such as the UK.

Using this framework, one can describe the demands of multiple agent populations with heterogeneous tastes for differentiated technologies. With this in place, we can begin to analyse the conditions under which coupled selection mechanisms trade off the network externalities associated with an incumbent technology system against the performance offered by new technology systems. It is worth noting that such a framework can be used to address a number of other interesting research questions, such as the emergence of multiple market niches, the sustainability of minor niches by consumers with strongly localised preferences, and the establishment of quasi-market niches for new technologies 
through government support. While the discussion of this paper is limited to that of technological succession, these other research questions are clearly related to the current discussion and will be explored in future papers. The next section considers the remaining elements which one might reasonably expect to find in a formal model of technological succession.

\section{Recasting the theory of technological lock-in}

We round off the current discussion by (re)considering the factors that inhibit agents in switching from an old technology to a new technology, even when, as under condition 1, the new technology is superior (fitter) to the old one. While this is a very different research question to that asked by the lock-in literature, many of the important contributions made to the literature on technological lock-in can be re-cast in discussions on the conditions under which inertia results in a technological lock-out of a new technology.

The following discussion draws upon the discussion presented in Windrum and Birchenhall (1998). The socio-technical matrix approach discussed in the preceding section is a useful theoretical and empirical tool for exploring the way in which a number of coupled selection mechanisms shape the emergence of a socio-technical niche. However, as Windrum and Birchenhall (1998) observe, the interactions and feedbacks that exist between these different selection mechanisms need to be carefully defined. As a first step they develop a partial model which solely focuses on the dynamics of the business environment. Here we outline those aspects of the model that are pertinent to the current discussion of technological succession.

Within a given regulatory and wider societal environment, the co-evolutionary interactions between consumer and firm learning in the business environment determine whether there is convergence to a single technology, or whether a number of differentiated technologies will emerge. Analytically, this translates into a model containing a pair of interacting populations with a fixed regulatory and societal environment. Like a predator-prey model, the learning activities of each population in the Windrum-Birchenhall model has a direct impact on the population learning of the other, as consumer preferences co-evolve with firms' technological learning.

The Windrum-Birchenhall model places particular emphasis on the link that exists between emulation, learning and technological evolution. Emulation, it is argued, is an important variable which affects both the rate and direction of technological innovation. Emulation is an interactive process that operates at two levels. As well as being important to the competitive strategies of individual firms it plays an important role in 
population learning. Firms learn by observing and emulating the successful technologies of their immediate rivals. This can range from emulation of specific characteristics to a much more general process whereby the very success of one firm signals that something is technically possible and, even more importantly, that a market for that product exists. It is fairly easy to monitor a rival's sales and market share, and in this way a firm can observe consumer reactions to a rival's product innovation. Patents are another potential source of information that is readily accessible. A firm may even purchase a rival's product and examine it in order to identify the design components that produce the particular performance characteristics and, in the last resort, reverse-engineer the product.

Emulative learning is particularly important in dynamic market environments where a number of alternative technological solutions are offered. The ability to emulate favourable characteristics helps us understand the extent to which firms tend to focus their innovative effort on certain 'key characteristics'. Mutual intra-organisational learning can lead to the establishment of a 'standard' technology that is seen to work and which is profitable. Associated with these technologies are sets of technological beliefs, understandings and capabilities. These support and maintain a standard, provided they are shared by the firms producing that technology. If a standard technology is seriously challenged, whether due to a change in endogenous circumstances or else an exogenous shock, a period of rapid innovation may commence. This challenging of the status quo could result in the emergence of a new technology that challenge the position of the dominant incumbent technology. Such a situation is illustrated in figure 5. A fitness measure is placed on the vertical axis while the 'technological distance' measure indicates the difference between the alternative characteristic bundles offered by each technology. The 'slopes' of a hill indicate a distribution of slightly differentiated versions around a technology, each with a slightly different fitness value.

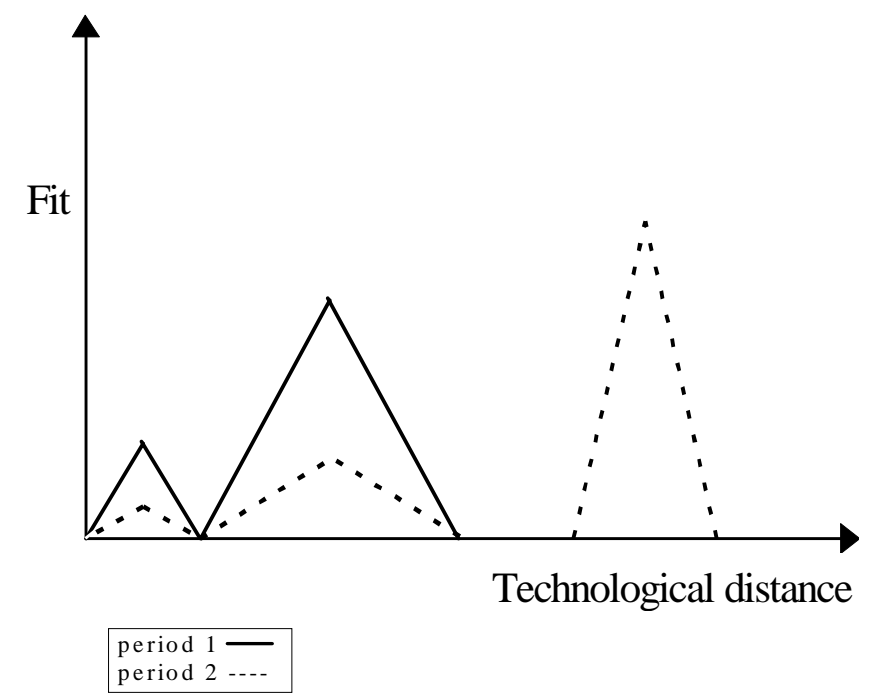

Figure 5. The changing contours of a fitness landscape in two periods. 
Two technologies fill this particular market niche (e.g. land-based transport) in period 1. The horizontal axis indicates that these two technologies are quite similar in terms of the characteristic bundles they offer, although one of the technologies is clearly fitter given the prevailing environmental conditions of this market niche in period 1. In period 2 the situation has changed quite dramatically. There is the emergence of a new technology which, as indicated by technological distance, offers quite a different combination of characteristics to the original two incumbents. Additionally, the fitness of this new technology is much higher in period 2 than either of the original incumbents. Indeed the fitness values for each of the original incumbents is much lower in period 2, suggesting that a significant change has occurred in the environmental conditions of this market niche. If the relative finesses are translated into market shares then the new technology would virtually take-over this market niche in period 2.

Windrum and Birchenhall observe that the dynamics of consumer demand are poorly researched, certainly when compared to the existing body of research on the supply side. Still, a useful start can be made by piecing together various aspects of that research which has been done to date. Of particular note is the work conducted on the types of information used by consumers as a basis for formulating their decisions. These include the work of Rogers and Shoemakker (1971) and Arthur (1989) on personal contacts, Rohlfs (1974) and Katz and Shapiro (1985) on network externalities, David and Greenstein (1990) on switching costs, and Farrell and Saloner (1985) on bandwagon effects. In various ways, these analyses concern themselves with factors leading to technological lock-in. However their discussion of factors leading to consumer inertia can be usefully combined with the socio-technical matrix approach in order to describe the conditions under which consumers will substitute the lock-in advantages associated with an incumbent technology with the benefits of the characteristics bundle offered by a new technology.

Piecing together these various strands of analysis, we can start to address a number of pertinent questions such as 'How can new consumers, with no previous experience to fall back on, evaluate the characteristics bundle offered by a new technology?'. Consumers may have some vague notions about the characteristics they would like to receive from a particular product. These may or may not be realistic; one's expectations of a technology may not be fulfilled by the products currently available. Even if initial expectations can be met, there remains the problem of how best to map these onto the characteristics offered by a new technology.

There exist a number of possible sources by which new consumers can gain information and build up knowledge about a product, its use, and the characteristics of competing technologies. Repeat purchasing is one obvious mechanism. This can prove a reasonably effective means of sampling a product, provided it is relatively inexpensive and is 
purchased on a regular basis (Porter, 1985). However its use is rather limited for new consumer technologies because these tend to be expensive when first introduced and are relatively long-lived. The efficacy of the mechanism is further offset, Porter observes, by frequent design innovations, which alter the characteristics bundle associated with the technology, and by an expansion of the market to new buyers with no previous experience of the product. Hence repeat purchasing is a limited method of gathering information about a new technology.

An alternative source of information is the purchasing decisions of other consumers. In effect a consumer attempts to draw lessons from those who have already tackled the same information problem. Here a parallel can be drawn with the emulative learning of firms. As is the case with firms, one would expect emulation to produce strong feedbacks between learning conducted at the individual and population levels. A frequently used source of information is personal contacts; friends and acquaintances who are knowledgeable - technically or otherwise - about a new technology product. The media is another key source of information. It disseminates a wealth of information through a variety of forms, including reports published by consumer groups, and articles and reviews appearing in newspapers and magazines. Furthermore, specialist consumer magazines frequently accompany the launch of a major new product technology. These are particularly interesting in that their explicit function is to test new products and provide background information on the trends that are occurring in the market. The more respected consumer magazines tend to be those that maintain a distance from producers' interests. Ideally they contain the personal findings and thoughts of consumers, published for the benefit of other consumers. Finally, although they are clearly less impartial, retailers and manufacturers can also provide consumers with detailed product specifications, advice regarding the use and maintenance of equipment, and information about appropriate ancillary hardware and software. 
A number of implications follow from these stylised facts bit the most important here is the possibility of a rapid switching in demand between alternative technologies. Yet, in practice, markets appear to be less volatile that one might initially expect. David and Greenstein (1990) identify a number of switching costs that may induce inertia. To begin with, the selection of a particular technology effectively commits a consumer to that technology for some time in the future. Knowing this, a consumer will try to purchase a technology that looks likely to survive. The costs of becoming a technological orphan can be extremely high. A commodity that is otherwise in good working order can become redundant through a lack of supporting software or ancillary hardware. Consumers then incur premature replacement costs as they are forced to purchase replacements. Of course it is very hard to predict the winners and losers of technological competitions. The best any individual can do is assess the relative market strengths of competing technologies - a key factor, as the lock-in literature is always keen to remind us - being the installed user base of each technology.

As well as physical replacement costs, technological redundancy can impose skillsrelated costs. Reaping the full benefits of an artefact frequently requires the acquisition and development of certain skills sets by the end user. Alternative technologies may require different user skills and, since design-specific skills are not costlessly attained, some consideration must be given to the reskilling costs associated with technological redundancy. These costs will vary according to the transferability of skills between different technologies.

Consumers may have to consider network externalities where the benefit that accrues to a user increases as the number of other users in the network grows. If a sufficiently large number of users have adopted a particular technology then the economic benefits justify the costs of adoption (Rohlfs, 1974; Katz and Shapiro, 1985). These increasing returns to adoption have been found to have important consequences in a number of sectors including telecommunications, telematics and computers (hardware and software). Again this indicates the importance of positive feedbacks and critical mass on preferences once individual benefit is linked to the choices made by other consumers.

Finally, consumers are not only linked in a direct fashion through personal relationships, they are also immersed in wider relationship networks that include institutional affiliations. Small (1994) has analysed how the prior commitments of institutions influence the choices if later adopters. In his study of the electronic mainframe computer he highlights the importance of social context; a context in which strong connections form between specific groups of users and producers. The case of the electronic computer saw the development of two alternative technologies, the analogue and the digital electronic computer. These rival technologies competed with each other for nearly thirty years. Each was supported by a different community of practitioners, the former being supported by the engineering community while the latter was supported by the scientific community. This support was based on a co-evolution of products and 
practices. For example, the analogue computer facilitated the development of traditional forms of engineering knowledge. For the first time engineers could construct sophisticated simulation models that were based on current theory. These were used to "simulate the physical system itself, to obtain a better understanding of the limits of engineering science, and to go beyond to obtain solutions in areas where physical phenomena were not well understood, nor predicted by extant theory" (Small, 1994, pp.44). This explains the strength that analogue computers had amongst the engineering fraternity. In joining the engineering community, an individual embraces a collection of practices and technological expectations that influence the choice of technology, the purpose to which it is put and the manner in which it is used.

Examining the various factors that may influence consumer decision-making, we can develop a reasonably sophisticated appreciation of preference formation in which tastes, learning, opportunities and the selection environment all combine in the decision-making process. Two key points emerge. Firstly, the dynamics of individual consumer choice cannot be understood in isolation of the population or 'group' context in which it occurs. Secondly there is a tendency for the dynamics driving consumer choice to reduce the number of technological variants over time. Having established a similar tendency for firm selections, one would perhaps expect a coupled firm-consumer learning system to generate a clustering around a limited number of alternative technologies rather than to be widely dispersed over a large number of alternative technologies. Perhaps this explains why technology switching, though it occurs only infrequently, is sudden and dramatic. This certainly forms an interesting research hypothesis.

This research will not simply apply the Windrum-Birchenhall co-evolution model to a new area of inquiry. In order to deal with the research issues raised in this paper, the model will need to be extended by endogenising at least one further selection environment. If one were to pursue the case of land-based transport, for instance, then an obvious extension would involve an endogenisation of the selections made by regulatory environment. As well as providing a more complete picture of co-evolutionary learning, and its impact on the course of technological innovation, this would enable a number of other research questions to be addressed. These include the extent to which different couplings of the regulation and consumer selection mechanisms alter the innovation dynamics of a system. A second issue is the relative frequency of selections. Changing consumer preferences may given an impulse to innovation in each period while policy changes occur less frequently and to operate under a quite different set of learning rules. What impact will differences in the relative frequency of knowledge updating have on the rate and direction of innovation? Such issues clearly influence the conditions under which the focus of technological innovation either remains locked-in to the existing technology, or else switches to a new, alternative technology option. 


\section{Summary}

The paper has sought to prepare the ground for the development of a formal model in which the dynamics of technological succession can be studied. The case has been argued for a return to Schumpeter's reading of economic history as one in which long periods of incremental innovation are punctuated by bursts of rapid technological change associated with the emergence of radically new technologies. While the dynamics of incremental innovation have been fairly well mapped out over the last couple of decades, the dynamics of technological transitions have been largely ignored.

In seeking to shift the research agenda, the paper examined the conditions under which the ecological concept of succession can be usefully transferred and made operational within a discussion of technological transitions. It was suggested that this transfer requires a careful definition of niche, species and fitness. A sustainable market niche exists when there is a user group that is attracted by the functionality offered by a technology. A species is thus a set of rival technologies that offer a degree of functional equivalency in use, such as competing modes of land-based transport. Fitness is a relative phenomenon that depends not only on the characteristics offered by a set of rival technologies but also the evaluation norms and selections made by a series of political, economic and other agents.

The paper sought to establish the set of necessary conditions for a technological succession. The first condition highlighted was the existence of an upper-bound to the returns to adoption associated with an established incumbent technology. Such a condition opens up at least the possibility of a consumer population being attracted by the potential of a later technology entrant. A second necessary condition is the emergence of a radically new, and interrelated, set of technological products and/or processes. A third condition is a new system architecture that controls the way in which these products and/or processes interact. The shift to a new system architecture is equivalent to the gestalt shift that underpins the emergence of a new scientific paradigm. While some elements of the incumbent system may be carried over in the new system, these are used in a completely new context and so may be viewed in a very different way. Turning to the demand-side, a technological transition requires substitutability between a positive network externality and characteristics. A new technology must offer performance characteristics which are either new or superior to those offered by the incumbent technology. The relative fitness of a new technology vis-à-vis that of an incumbent technology depends on the size of the network externality, the characteristics offered by each technology, and users' valuations of those characteristics.

Unfortunately, in the presence of heterogeneous preferences, a simple analytically tractable solution is unlikely to exist in all but the simplest of circumstances. Multiple equilibria solutions may exist in which it is impossible to predict ex ante whether there 
will be a technological succession, a technological lock-out, or the emergence of multiple market niches. First, multiple equilibria solutions will exist, even when the performance characteristics of one technology are absolutely superior to those of another, if there is a high frequency of intermediate valuations within the consumer population. Second, rival technologies typically offer different relative strengths across a set of performance characteristics. Again, given heterogeneous preferences, it is impossible to predict ex ante whether a technological succession will occur.

One way of tackling the problem is to build a simulation model that takes into account the heterogeneous preferences of different groups of agents, the couplings of the selections made by these groups and the relative power of different agents. To this end the paper outlined a socio-technical matrix approach for the study of technological transitions that may form a useful basis for such a model. The approach comprises two elements. The first is a matrix of technical characteristics in which the values of characteristics offered by rival technological options are located. The second element is an explicit consideration of the preferences the various agents who make their selections over the characteristics matrix. By formally modelling this set of coupled selection mechanisms one can appreciate the political, economic and wider social dynamics of technological succession. Finally, the paper sought to recast, in this new context, the important insights on increasing returns to adoption and path dependency made within the lock-in literature. These insights help us identify some key sources of inertia that may prevent a technological transition taking place. With these elements in place, it has been argued, we can develop a model that helps us analyse the way in which technological learning generates long period of stasis punctuated by rapid bursts of technological change. 


\section{Bibliography}

Abernathy W.J., and Clark K.B., 1985, Innovation: mapping the winds of creative destruction, Research Policy, 14, pp.3-22.

Abernathy, W.J. and Utterback, J.M., 1975, A dynamic model of product and process innovation, Omega, 3, pp.639-656.

Andersen, E.S., 1990, Techno-economic paradigms as shared specifications of typical interfaces between producers and users, Mimeo.

Anderson, P. and Tushman, M., 1990, Technological discontinuities and dominant designs: a cyclical model of technological change, Administrative Science Quarterly, 35, pp.604-633.

Anderson, S.P., de Palma, A., Thisse, J-F, 1992, Discrete Choice Theory of Product Differentiation, MIT Press: Cambridge, Mass.

Archibald, G.C. and Eaton, B.C., 1989, Two applications of characteristics theory, in Freiwel (ed.) The Economics of Imperfect Competition and Employment: Joan Robinson and Beyond, Macmillan: London.

Arthur, B., Ermoliev, Y. and Kaniovski, Y., 1987, Path dependent processes and the emergence of macrostructure, European Journal of Operational Research, 30, pp.294303.

Arthur, B., 1988, Competing technologies: an overview, in G. Dosi, C. Freeman, R. Nelson, G. Silverberg and L. Soete (ed.), Technical Change and Economic Theory, Pinter: London.

Arthur, B., 1989, Competing technologies, increasing returns and lock-in by historical events, Economic Journal, 99, pp.116-131.

Autocar, 1999, Sweet cell of success, report by Jesse Crosse, 3rd February 1999, pp.5051.

Banerjee, A., 1992, A simple model of herd behaviour, Quarterly Journal of Economics, 108, pp.797-817.

Bassanini, A. and Dosi, G., 1998, Competing technologies, international diffusion and the rate of convergence to a stable market structure, IIASA Interim Report, IR-98-012, IIASA: Laxenbourg. 
Bikchnadani S., Hirschleifer, D., Welch, I., 1992, A theory of fads, fashion, custom and cultural change as informational cascades, Journal of Political Economy, 100, pp.9921026.

Bruckner, E., Ebeling, W., Jiménez Montaño, M.A. and Scharnhorst, A., 1994, Hyperselection and Innovation Described by a Stochastic Model of Technological Evolution, in L. Leydesdorff and P. vd Besselaar (ed.), Evolutionary Economics and Chaos Theory, Pinter: London.

Choi, S.C., DeSarbo, W.S. and Harker, P., 1990, Product positioning under price competition, Management Science, 36, pp.175-199.

Clark, K.B., 1985, The interaction of design hierarchies and market concepts in technological evolution, Research Policy, 14, pp.235-251.

Clements, F.E., 1936, Nature and the structure of the climax, Journal of Ecology, 24, pp.252-284.

Cox, C.B. and Moore, P.D., 1985, Biogeography: An Ecological and Evolutionary Approach, Fourth Edition, Blackwell Scientific Publications: Oxford.

David, P., 1985, Clio and the economics of QWERTY, American Economic Review Papers and Proceedings, 75, pp.332-336.

David, P. and Greenstein, S., 1990, The economics of compatibility standards: an introduction to recent research, Economics of Innovation and New Technology, 1, pp.3-41.

Deuten, J., Rip, A. and Jelsma, J., 1997, Societal embedding and product creation management, Technology Analysis \& Strategic Management, Vol. 8, 2, pp.131-148.

Eldridge, N., 1987, Life Pulse: Episodes from the Story of the Fossil Record, Penguin: London.

Farrell, J. and Saloner, G, 1985, Standardisation, compatibility and innovation, Rand Journal of Economics, 16, pp.70-83.

Farrell, J. and Saloner, G, 1986, Installed base and compatibility: innovation, product announcements, and predation, American Economic Review, 76, pp.940-955.

Feistel, R. and Ebeling, W., 1989, Evolution of Complex Systems, VEB Deutscher Verlag der Wissenschaften: Berlin.

Fisher, R. A., 1930, The Genetical Theory of Natural Selection, Clarendon Press: Oxford. 
Foray, D., 1989, Les modeles de competition technologique, une revue de la litterature, Revue d'Economie Industrielle, 48, pp.16-34.

Foray, D. and Grübler, A., 1990, Morphological analyses, diffusion and lock-out of technologies: ferrous casting in France and FRG, Research Policy, 19, pp.535-550.

Freeman, C., Clark J. and Soete L., 1982, Unemployment and Technological Innovation: a Study of Long Waves in Economic Development, Pinter: London.

Freeman, C. and Perez, C., 1988, Structural crises of adjustment, business cycles and investment behaviour, in G. Dosi, C. Freeman, R. Nelson, G. Silverberg and L. Soete (ed.), Technical Change and Economic Theory, Pinter: London.

Frenken, K., P.P. Saviotti, M. Trommetter, 1999. Variety and niche creation in aircraft, helicopters, motorcycles and microcomputers, Research Policy, 28, forthcoming.

Frenken, K. and Verbart, O., 1998, Simulating paradigm shifts using a lock-in model, in P. Ahrweiler and N. Gilbert (ed.), Computer Simulations in Science and Technology Studies, Springer-Verlag: Berlin.

Gould, S.J. and Eldridge, N., 1977, Punctuated equilibria: the tempo and mode of evolution reconsidered, Paleobiology, 3, pp.115-151.

Grindley, P., 1992, Standards, Business Strategy and Policy A Casebook, London Business School: London.

Grübler A., Nakiecenovic, N., and Posch, M., 1988, Methods of estimating s-shaped growth functions: algorithms and computer programmes, IIASA Working Paper, IIASA: Laxembourg.

Grübler, A., 1990, The Rise and Decline of Infrastructures. Dynamics of Evolution and Technological Change in Transport, Physica-Verlag: Heidelberg.

Henderson, R. and Clark, K., 1990, Architectural innovation: the reconfiguration of existing product technologies and the failure of established firms, Administrative Quarterly Journal, 35, pp.9-30.

Hotelling, H., 1929, Stability in competition, Economic Journal, 39, pp.41-57.

Islas, J., 1997, Getting around a lock-in in electricity generating systems: the example of the gas turbine, Research Policy, pp.49-66.

Jonard, N., 1999, Sketch of an analytical model of technological transition, Mimeo. 
Katz, M. and Shapiro, C., 1985, Network externalities, competition and compatibility, American Economic Review, 75, pp.424-440.

Katz, M. and Shapiro, C., 1986, Technology adoption in the presence of network externalities, Journal of Political Economy, 94, pp.822-841.

Kuhn, T.S., 1962, The Structure of Scientific Revolutions, University of Chicago: Chicago.

Lancaster, K., 1971, Consumer Demand: A New Approach, Columbia University Press: Columbia.

Lundvall, B-A., 1992, National Systems of Innovation, Pinter: London.

Metcalfe, S., 1984, Technological innovation and the competitive process, in P. Hall, (ed.), Technology, Innovation and Economic Policy, P. Allen: London.

Nelson, R. (ed.), 1993, National Innovation Systems: A Comparative Analysis, Oxford University Press: Oxford.

Nelson R., and Winter, S., 1982, An Evolutionary Theory of Economic Change, Harvard University Press: Cambridge, Mass.

Nicolis, G. and Prigogine, I., 1977, Self-organisation in Non-Equilibrium Systems, Wiley Interscience: New York.

Odum, E.P., 1969, The strategy of ecosystem development, Science, 164, pp.262-270.

Porter, M., 1985, Competitive Advantage: Creating and Sustaining Superior Performance, Free Press: New York.

Rip, A., 1992, A quasi-evolutionary model of technological development and a cognitive approach to technology policy, in Rivista di Studi Episemologici e Sociali sulla Scienza e la Tecnologia, 2, pp.60-103.

Rip, A. and Kemp, R., 1998, Technological change, in Human Choice and Climate Change, Vol. 2. Resources and Technology, S. Rayner and E. Malone (ed.), Batelle Press: Columbus, Ohio.

Rogers, E.M. and Shoemakker, F., 1971, Communication of Innovations: A Crosscultural Approach, 2nd Edition, Free Press: New York.

Rohlfs, J., 1974, 'A theory of independent demand for a communication system', Bell Journal of Economics, 5, pp.16-37. 
Rosenberg, N., 1982, Inside the Black Box: Technology and Economics, Cambridge University Press: Cambridge.

Rosenkopf, L. and Tushman, M., 1994, The coevolution of technology and organisation, in J. Baum and J. Sing (ed.), Evolutionary Dynamics of Organisations, Oxford University Press: Oxford.

Saviotti, P.P., 1988, The measurement of changes in technological output, in Van Raan, A.F.J. (ed.), Handbook of Quantitative Studies of Science and Technology, (NorthHolland: Amsterdam.

Schumpeter, J.A., 1939, Business Cycles: A Theoretical, Historical and Statistical Analysis of the Capitalist Process, McGraw-Hill, New York.

Shy, O., 1996, Technology revolutions in the presence of network externalities, International Journal of Industrial Organisation, 14, pp.785-800.

Silverberg, G., 1988, Modelling economic dynamics and technical change: mathematical approaches to self-organisation and evolution, in G. Dosi, C. Freeman, R. Nelson, G. Silverberg and L. Soete, (ed.), Technical Change and Economic Theory, Pinter: London and New York.

Small, J., 1994, 'Engineering, technology and design: the post-second world war development of electronic analogue computers', History and Technology, 11, pp.38-48.

Sterman, J.D., 1985, The growth of knowledge: testing a theory of scientific revolutions with a formal model, in Technological Forecasting and Social Change, 28, pp.93-122.

Swann, G. M. P., 1990, Product competition and the dimensions of product space, International Journal of Industrial Organisation, 8, pp.281-295.

Swann, G. M. P., 1998, Are network externalities linear?, Unpublished paper, Manchester Business School.

Tice, G., 1988, Are software standards wasted efforts?, IEEE Software, 8, pp.14-17.

Tushman, M. and Murmann, J.P., 1998, Dominant designs, technology cycles and organisational outcomes, Mimeo.

Utterback, J., 1979, The dynamics of product and process innovation in industry, in C.T. Hill and J. Utterback (ed.), Technological Innovation for a Dynamic Economy, Pergamon Press: New York.

Utterback, J. and Suarez, F., 1993, Innovation, competition, and industry structure, Research Policy, 22, pp.1-21. 
Weber, K.M., 1996, Combined heat and power in the UK and Germany, IPTS Technical Reoprt Series, EUR 17280 EN.

Williamson, O.E., 1975, Markets and Hierarchies: Analysis and Anti-Trust Implications, Free Press: New York.

Windrum, P., 1998, The collective invention of the world-wide web, Report to DGXII, Colline Project, December 1998, available at <http://meritbbs.unimaas.nl/staff/ windrum.html >.

Windrum, P., Birchenhall, C., 1998, Is life cycle theory a special case?: dominant designs and the emergence of market niches through co-evolutionary learning', Structural Change and Economic Dynamics, 9, pp.109-134.

Winter, S., 1984, Schumpeterian competition in alternative technological regimes, Journal of Economic Behaviour and Organisation, 5, pp.287-320. 